\title{
Monomer Reactivity Ratios and Q,e-Values of Trialkylsilyl Acrylates and Methacrylates
}

\author{
Hirotada FuJIwaRA, Tadashi NaRITA, ${ }^{\dagger}$ and Hiroshi Hamana \\ Department of Applied Chemistry, Saitama Institute of Technology, \\ 1690 Fusaiji, Okabe, Saitama 369-0293, Japan
}

(Received May 8, 2000; Accepted September 13, 2000)

\begin{abstract}
KEY WORDS Monomer Reactivity Ratios / Q,e / Tributylsilyl Methacrylate / Tri(iso-propyl)silyl Methacrylate / Tri(iso-butyl)silyl Methacrylate / Tributylsilyl Acrylate / Tri(iso-propyl)silyl Acrylate /
\end{abstract}

\begin{abstract}
Copolymerization of silicon-containing vinyl monomer and fluorine-containing vinyl monomer might be an easy way to prepare hybrid polymers bearing silicon and fluorine atoms. Though the polymerization reactivity of fluorinated vinyl monomers has been studied intensively, ${ }^{1}$ little information on silicon-containing vinyl monomers of fundamental structure is available. ${ }^{2}$ To investigate the polymerization of trialkylsilyl acrylates and methacrylates, $Q, e$ of monomers should be useful for estimating the reactivity of monomers. No $Q, e$ of trialkylsilyl acrylates or methacrylates was available though those of tributyltin methacrylate and acrylate are reported to be $Q=0.852, e=-0.197$, and $Q=0.235$, $e=-0.401$, respectively. ${ }^{3}$

This paper report the monomer reactivity ratio and $Q$, $\boldsymbol{e}$ of trialkylsilyl methacrylates $\mathbf{1}$ and acrylates $\mathbf{2}$, as shown in Scheme 1.
\end{abstract}

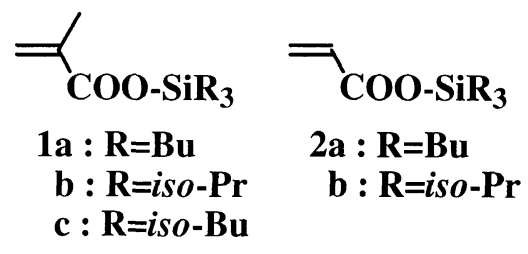

Scheme 1.

\section{EXPERIMENTAL}

Tributylsilyl methacrylate (1a), triisopropylsilyl methacrylate (1b), triisobutylsilyl methacrylate (1c), tributylsilyl acrylate (2a) and triisopropylsilyl acrylate (2b) (from YUKI GOSEI KOGYO CO., LTD.) were refluxed over calcium hydride and distilled under reduced pressure. Boiling points of the monomers are: 1a, bp $126^{\circ} \mathrm{C} / 4$ $\mathrm{mmHg}\left(5.3 \times 10^{2} \mathrm{~Pa}\right) ; \mathbf{1 b}$, bp $88^{\circ} \mathrm{C} / 3 \mathrm{mmHg}\left(4.0 \times 10^{2} \mathrm{~Pa}\right)$; 1c, bp $75^{\circ} \mathrm{C} / 2 \mathrm{mmHg}\left(2.7 \times 10^{2} \mathrm{~Pa}\right) ; \mathbf{2 a}$, bp $80^{\circ} \mathrm{C} / 2 \mathrm{mmHg}$ $\left(2.7 \times 10^{2} \mathrm{~Pa}\right)$ and $2 \mathbf{b}$, bp $90^{\circ} \mathrm{C} / 5 \mathrm{mmHg}\left(6.7 \times 10^{2} \mathrm{~Pa}\right)$. The monomers were stored under a nitrogen atmosphere. Benzoyl peroxide (BPO) was recrystallized from chloroform. Styrene was purified by the usual method. Copolymerizations of trialkylsilyl acrylates and methacrylates $\left(M_{1}\right)$ with styrene $\left(M_{2}\right)$ were carried out in bulk with sealed tube under nitrogen atmosphere at $80^{\circ} \mathrm{C}$ in-

${ }^{\dagger}$ To whom correspondence should be addressed. itiated by BPO. After an appropriate time the reaction was terminated by bubbling oxygen. The copolymer was isolated by reprecipitation in cold methanol, and dried to constant weight. Copolymer composition of each monomer unit in copolymer was obtained from ${ }^{1} \mathrm{H}$ NMR measurement. ${ }^{1} \mathrm{H}$ and ${ }^{13} \mathrm{C}$ NMR was measured with a JEOL JNM-ECP 500. Monomer reactivity ratios were determined by the Kelen-Tüdös method.

\section{RESULTS AND DISCUSSION}

Homopolymers of $\mathbf{1 a}, \mathbf{1 b}, \mathbf{1 c}, \mathbf{2 a}$, and $\mathbf{2 b}$ were produced in yields of $83,67,70,53$, and $69 \%$, respectively though conversions of monomers measured by ${ }^{1} \mathrm{H}$ NMR were almost quantitative. This is probably because low molecular weight polymers fail to be precipitated and filtered off since the solubility of the homopolymers is higher than that of poly(methyl acrylate) or poly(methyl methacrylate).

Copolymerizations of trialkylsilyl acrylates and methacrylates with styrene (St) were carried out in bulk at $80^{\circ} \mathrm{C}$ initiated by BPO. Details of the copolymerizations of $\mathbf{2 a}$ with St and copolymer compositions are shown in Table I.

The monomer-copolymer composition curve of $\mathbf{2 a} / \mathrm{St}$ is shown in Figure 1. The solid line in Figure 1 is the calculated monomer-copolymer composition curve from the monomer reactivity ratios, $r_{1}$ and $r_{2}$, as calculated from the experimental results by the Kelen-Tüdös method. Similar results were obtained for $\mathbf{1 a}, \mathbf{1 b}, \mathbf{1 c}$, and $\mathbf{2 b}$ with St.

Details of monomer reactivity ratios and $Q, e$ of trial-

Table I. Radical copolymerization of $\mathbf{2 a}\left(\mathrm{M}_{1}\right)$ with styrene $\left(\mathrm{M}_{2}\right)$

\begin{tabular}{|c|c|c|c|c|}
\hline $\mathbf{2 a}$ & $\mathrm{St}$ & Yield & {$\left[\mathrm{M}_{1}\right]$ in monomer } & {$\left[\mathrm{M}_{1}\right]$ in copolymer } \\
\hline $\mathrm{mmol}$ & $\overline{\mathrm{mmol}}$ & wt\% & $\mathrm{mol} \%$ & $\mathrm{~mol} \%$ \\
\hline 2 & 18 & 1.6 & 10 & 13.5 \\
\hline 2 & 18 & 9.6 & 10 & 12.6 \\
\hline 5 & 15 & 0.6 & 25 & 26.0 \\
\hline 5 & 15 & 13.3 & 25 & 26.7 \\
\hline 10 & 10 & 0.8 & 50 & 40.9 \\
\hline 10 & 10 & 11.2 & 50 & 47.4 \\
\hline 15 & 5 & 1.0 & 75 & 53.1 \\
\hline 15 & 5 & 8.4 & 75 & 47.5 \\
\hline 18 & 2 & 0.4 & 90 & 68.5 \\
\hline 18 & 2 & 10.9 & 90 & 78.7 \\
\hline
\end{tabular}


Table II. Monomer reactivity ratios and $Q$, $e$ of trialkylsilyl (meth)acrylates $\left(\mathrm{M}_{1}\right)$ with styrene $\left(\mathrm{M}_{2}\right)$

\begin{tabular}{llcccc}
\hline \multicolumn{1}{c}{$\mathrm{M}_{1}$} & & $r_{1}$ & $r_{2}$ & $Q_{1}$ & $e_{1}$ \\
\hline $\mathrm{CH}_{2}=\mathrm{C}\left(\mathrm{CH}_{3}\right) \mathrm{COOSi}\left(\mathrm{C}_{4} \mathrm{H}_{9}\right)_{3}$ & $\mathbf{1 a}$ & 0.17 & 0.83 & 0.39 & 0.61 \\
$\mathrm{CH}_{2}=\mathrm{C}\left(\mathrm{CH}_{3}\right) \mathrm{COOSi}\left(i-\mathrm{C}_{3} \mathrm{H}_{7}\right)_{3}$ & $\mathbf{1 b}$ & 0.24 & 0.57 & 0.57 & 0.60 \\
$\mathrm{CH}_{2}=\mathrm{C}\left(\mathrm{CH}_{3}\right) \mathrm{COOSi}\left(i-\mathrm{C}_{4} \mathrm{H}_{9}\right)_{3}$ & $\mathbf{1 c}$ & 0.20 & 0.70 & 0.47 & 0.59 \\
$\mathrm{CH}_{2}=\mathrm{CHCOOSi}\left(\mathrm{C}_{4} \mathrm{H}_{9}\right)_{3}$ & $\mathbf{2 a}$ & 0.17 & 0.63 & 0.49 & 0.69 \\
$\mathrm{CH}_{2}=\mathrm{CHCOOSi}\left(i-\mathrm{C}_{3} \mathrm{H}_{7}\right)_{3}$ & $\mathbf{2 b}$ & 0.39 & 0.49 & 0.74 & 0.49 \\
$\mathrm{CH}_{2}=\mathrm{C}\left(\mathrm{CH}_{3}\right) \mathrm{COOCH}_{3}$ & & & & 0.74 & 0.40 \\
$\mathrm{CH}_{2}=\mathrm{C}\left(\mathrm{CH}_{3}\right) \mathrm{COOC}_{4} \mathrm{H}_{9}$ & & & & 0.82 & 0.28 \\
$\mathrm{CH}_{2}=\mathrm{CHCOOCH}_{3}$ & & & & 0.45 & 0.64 \\
$\mathrm{CH}_{2}=\mathrm{CHCOOC}_{4} \mathrm{H}_{9}$ & & & 0.38 & 0.85 \\
\hline
\end{tabular}



Figure 1. Copolymer composition curve for $\mathbf{2 a}$ and styrene.

kylsilyl acrylates and methacrylates are shown in Table II. The $Q$ of trialkylsilyl methacrylates are smaller than that of methyl methacrylate (MMA) $(Q=0.74)$; which indicates the resonance effect of trialkylsilyl group to be lower compared to that of the ester methyl group of MMA. $e$ of trialkylsilyl methacrylates is larger than that of MMA $(e=0.40)$. The trialkylsilyl group gives higher polar effect on vinyl group. $Q, e$ of trialkylsilyl acrylates are similar to those of methyl and butyl acrylate.

Duran et al. ${ }^{4}$ reported monomer reactivity ratios $\left(r_{1}=\right.$ $\left.0.710, r_{2}=0.890\right)$ of $t$-butyldimethysilyl methacrylate $\left(\mathrm{M}_{1}\right)$ with MMA $\left(\mathrm{M}_{2}\right)$, which give two sets of $Q, e$ for $\mathrm{M}_{1}$; $Q=1.09, e=1.08$, and $Q=0.63, e=-0.28$. $Q$ of the first set appears too large and $e$ of the second set too small. ${ }^{13} \mathrm{C}$ NMR chemical shifts of $\beta$-carbons of $\mathbf{1 a}, \mathbf{1 b}$, and 1c were $125.6,126.1$, and $125.8 \mathrm{ppm}$, respectively, almost the same as that of MMA (125.3 ppm) considering experimental error; which suggests $e$ of trialkylsilyl methacrylates to possibly be similar to that of MMA.

Acknowledgments. The authors would like to express their gratitude to Messrs. M. Takahashi and M. Nomura for their experimental assistance.

\section{REFERENCES}

1. T. Narita, Progr. Polym. Sci., 24, 1095 (1999).

2. H. R. Kricheldorf, Ed., "Silicon in Polymer Synthesis", Springer, 1996.

3. B. K. Garg, J. Corredor, and R. V. Subramanian, J. Macromol. Sci. Chem., A 11, 1567 (1977).

4. P. Durand, A. Margaillan, M. Camail, and J. L. Vernet, Polymer, 35, 4392 (1994). 